\title{
Caries is Associated with Asthma and Epilepsy
}

Ida Anjomshoaa ${ }^{a}$

Margaret E. Cooper ${ }^{b}$

Alexandre R. Vieira ${ }^{a}$

\section{ABSTRACT}

Objectives: There is evidence of association between systemic diseases and oral conditions, although it is not clear if these are direct or mediated by underlying factors such as health behaviors. The aim of this work was to evaluate whether self-reported systemic diseases were associated with caries experience.

Methods: Medical history data and caries experience (DMFT and DMFS; Decayed, Missing due to caries, Filled Teeth/Surface) were obtained from the University of Pittsburgh School of Dental Medicine Dental Registry and DNA Repository. Information on 318 subjects (175 females and 143 males) was evaluated. Regression analysis was used to test for association between caries experience and disease status.

Results: The stronger associations were found between caries experience and asthma and epilepsy. With respect to asthma, DMFT above $15\left(R^{2}=0.04\right)$ and DMFS above $50\left(R^{2}=0.02\right)$ were associated. After controlling for gender differences in asthma, the associations remained strong $\left(R^{2}\right.$ $=0.05$ for both DMFT and DMFS). For epilepsy, DMFT above $15\left(R^{2}=0.18\right)$ and DMFS above $50\left(R^{2}=\right.$ $0.14)$ were associated.

Conclusions: Asthma and epilepsy are associated with higher caries experience. (Eur J Dent 2009;3:297-303)

Key words: Caries; Asthma; Epilepsy; Cardiovascular Diseases; Diabetes.

-1. Department of Oral Biology, School of Dental Medicine, University of Pittsburgh, PA, USA.

b Department of Oral Biology, Center for Craniofacial and Dental Genetics, School of Dental Medicine, University of Pittsburgh, PA, USA.

- Corresponding author: Alexandre R. Vieira 614 Salk Hall, Department of Oral Biology, School of Dental Medicine, University of Pittsburgh, 3501 Terrace Street, Pittsburgh, 15261, PA, USA.

Phone: (412) 383-8972

Fax: (412) 624-3080

E-mail: arv11apitt.edu

\section{INTRODUCTION}

Over the last decade, the possible role of oral health as a risk factor for systemic disease has been highlighted in multiple instances. On one hand, it is suggested that every individual should visit her/his dentist at least once a year. ${ }^{1}$ However, poor and minority individuals, who experience greater levels of both dental and systemic disease, frequently face cost and other systemlevel barriers to obtain care in the private practice dental delivery system. ${ }^{2-4}$ For these individuals, 
non-traditional sources of dental care, such as physician offices, other medical settings, and the hospital emergency room, have been alternative options. ${ }^{5}$ On the other hand, according to a crosssectional, random digit telephone survey which was sponsored by the CDC and all U.S. states and territories in 2003, ${ }^{6}$ although periodic medical examinations of healthy individuals aiming to foster patients' good health is proposed, ${ }^{7}$ only $2.6 \%$ of 97,001 healthy adults reported have received primary prevention.

Whereas issues related to access to care need to be addressed, dentistry has an important role in promoting the overall health. While physicians are missing opportunities to provide primary prevention, the promotion of oral health has been suggested as a way to promote systemic health, since there is a possible role of oral infections as a risk factor for systemic disease. Caries remains the most prevalent non-transmissible infectious disease in the U.S. and in the rest of the world. ${ }^{8}$ Research on the relationship between caries and systemic diseases has provided evidence that caries may be associated with cardiovascular diseases, ${ }^{9}$ esophageal cancer ${ }^{10}$ and asthma. ${ }^{11}$

A better understanding of the possible relationships between caries experience and systemic diseases may provide new insight on the influences of oral health on systemic health. Our goal was to study a high risk population to investigate if caries experience indicators are associated with concomitant systemic disease.

\section{MATERIALS AND METHODS}

All subjects were participants in the Dental Registry and DNA Repository (DRDR) of the University of Pittsburgh School of Dental Medicine. Starting in September of 2006, all individuals that seek treatment at the University of Pittsburgh School of Dental Medicine have been invited to be part of the registry. These individuals give written informed consent authorizing the extraction of information from their dental records. This project is approved by the University of Pittsburgh Institutional Review Board. In December 2007, data from 318 individuals with good data completion was extracted from the registry for this project.

\section{Statistical methods}

For preliminary analysis, we used analysis of variance (ANOVA) and student t-tests to inves- tigate gender and ethnicity differences in caries experiences. Simple chi-square tests were used to investigate gender and ethnicity differences in each of the possible diseases lasthma, epilepsy, diabetes, cardiovascular disease (CVD), infections, medication uptake and tobacco use). We used logistic regression analysis to investigate maineffect models to predict disease status (diseases included: asthma, diabetes, epilepsy, CVD). The main effects-confounders included age, gender, ethnicity, tobacco usage, concomitant infections and medication intake. Interactions between the main effects were also completed. Model selection was determined largely by the adjusted $\mathrm{R}^{2}$ statistic that calculates the variance explained by the main effects and their interactions. For the purposes of teasing out ethnic differences, the logistic regression was carried out on those 292 patients reported as Caucasian or African-American. The best-fitting models were determined for the systemic diseases incorporating association with caries experience by the following formula: Disease $=\alpha+\beta_{1}{ }^{*} X_{1}+\beta_{2}{ }^{*} X_{2}+\ldots . .+\beta_{n}{ }^{*} X_{n}+\beta_{1}{ }^{*} X_{i}{ }^{*} X_{j}+\ldots$ $+\beta$ where $X n$ are the main effects/confounders.

\section{RESULTS}

Details of the population studied are presented in Table 1. The mean age of patients was 41.7 years with ages ranging from 17 to 84 years. The mean DMFT (Decayed, Missing teeth due to caries, Filled Teeth) score was 15.35 and ranged from 0 to 28 . The mean DMFS (Decayed, Missing teeth due to caries, Filled Surface of a tooth) score was 49.25 and ranged from 0 to 128 . Only 18 individuals (6\%) were caries free. African Americans showed a non significant slightly higher caries experience than Caucasians. There were no significant effects of ethnicity on DMFS or DMFT (ANOVA P=0.32). Gender differences were observed in asthma $(P=0.04)$ with more females with asthma than expected and in concomitant infections ( $P=0.02)$ with more males with infections than expected. All other gender difference analyses had P-values $>0.28$.

Our logistic regression results are summarized on Table 2, which shows univariate models, and Table 3, which shows the best multivariate models. DMFT, DMFS and age were centered at their mean values ( 15 for DMFT, 50 for DMFS and 43 years for age). Caries experience was associated with asthma (DMFT with $\mathrm{R}^{2}=0.04, \mathrm{P}=0.01$ and 
DMFS with $\left.R^{2}=0.02, P=0.008\right)$. Asthma was associated with females $\left(R^{2}=0.02 ; P=0.04\right)$. Since asthma showed gender effects in this population, we controlled for gender to achieve a more parsimonious model resulting in DMFT with $\mathrm{R}^{2}=0.052, \mathrm{P}=0.01$ and DMFS with $R^{2}=0.046, P=0.01$. Asthma showed no medication intake effects (with $R^{2}=0.004, P=0.41$ ). Epilepsy was also associated with caries experi- ence (DMFT with $R^{2}=0.18, P=0.001$, and DMFS with $\left.R^{2}=0.14, P=0.0008\right)$. Independently, medication intake $(\mathrm{Rx})$ was also associated with epilepsy. In controlling for medication, DMFS and DMFT were still associated with epilepsy: the model with DMFT and $R x$ had $R^{2}=0.20$ with $P=0.003$ for the parameter estimate for DMFT but $P=0.19$ for the parameter estimate for Rx and the model with DMFS

Table 1. The study population of 318 individuals.

\begin{tabular}{|c|c|c|c|c|c|c|c|}
\hline & $n$ & $\begin{array}{l}\text { Age }^{1} \text { (years) } \\
\text { Average/ } \\
\text { Range }\end{array}$ & $\begin{array}{l}\text { Caries } \\
\text { DMFT/ } \\
\text { DMFS }\end{array}$ & $\begin{array}{c}\text { Females (n) } \\
\text { DMFT/ } \\
\text { DMFS } \\
\end{array}$ & $\begin{array}{c}\text { Males (n) } \\
\text { DMFT/ } \\
\text { DMFS }\end{array}$ & $\begin{array}{c}\text { Smokers (n) } \\
\text { DMFT/ } \\
\text { DMFS }\end{array}$ & $\begin{array}{c}\text { Non-smokers (n) } \\
\text { DMFT/ } \\
\text { DMFS }\end{array}$ \\
\hline Whole population & 318 & $\begin{array}{c}(311) \\
41.7 / 17-84\end{array}$ & $\begin{array}{c}\text { (318) } \\
15.35 / 49.25\end{array}$ & $\begin{array}{c}(175) \\
15.29 / 49.42\end{array}$ & $\begin{array}{c}(143) \\
15.42 / 49.05\end{array}$ & $\begin{array}{c}(84) \\
18.57 / 61.40\end{array}$ & $\begin{array}{c}(234) \\
14.30 / 45.59\end{array}$ \\
\hline Ethnicity & & & & & & & \\
\hline Caucasian & 246 & $42.54 / 17-83$ & $15.60 / 49.41$ & $14.96 / 47.49$ & $16.39 / 51.77$ & $19.51 / 64.52$ & $14.13 / 43.75$ \\
\hline African American & 46 & 46.7/19-84 & $16.24 / 55.93$ & $18.19 / 64.67$ & $13.47 / 43.53$ & $13.67 / 42.73$ & $17.48 / 62.32$ \\
\hline Other/Unknown² & 26 & $38.5 / 22-73$ & $12.4 / 42.27$ & $13.75 / 43.67$ & $11.29 / 41.07$ & $24.00 / 97.00$ & $11.46 / 37.71$ \\
\hline Asthma & 48 & $43.31 / 18-84$ & $18.33 / 60.25$ & $18.79 / 61.88$ & $17.33 / 56.67$ & $9.11 / 47.09$ & $7.66 / 37.10$ \\
\hline $\mathrm{CVD}^{3}$ & 108 & $53.73 / 18-84$ & $18.41 / 65.91$ & $19.74 / 71.36$ & $16.86 / 59.58$ & $20.29 / 75.96$ & $17.87 / 63.04$ \\
\hline Diabetes & 20 & $57.05 / 18-84$ & $19.55 / 70.70$ & $19.55 / 69.36$ & $19.56 / 72.33$ & $18.50 / 79.50$ & $19.67 / 69.72$ \\
\hline Epilepsy ${ }^{4}$ & 13 & $48.23 / 24-68$ & $23.69 / 87.23$ & $22.33 / 81.00$ & $24.86 / 92.57$ & $24.50 / 91.75$ & 23.33/85.22 \\
\hline Infections & 20 & $47.90 / 27-72$ & $19.55 / 71.40$ & $19.00 / 76.17$ & $19.79 / 69.36$ & $19.57 / 61.86$ & $19.54 / 76.54$ \\
\hline Medications & 144 & 49.79/18-84 & $18.15 / 61.88$ & $7.84 / 37.77$ & $6.26 / 32.07$ & $20.86 / 73.81$ & $17.25 / 57.91$ \\
\hline
\end{tabular}

17 individuals did not have age recorded: 4 tobacco users (2 male), 2 CVD (1 male), 3 Medications (1 male), none reported asthma, diabetes, epilepsy or infections

${ }^{2}$ Other ethnicities reported: Asian (10), Native American(1), Hispanic (2), India/Middle East (9), Unknown(4)

${ }^{3}$ Cardiovascular diseases (CVD) include coronary heart disease, hypertension, stroke, and congenital anomalies.

${ }^{4} 1$ unknown

Table 2. Univariate modeling of diseases: Using single effects.

\begin{tabular}{|c|c|c|c|c|c|c|c|c|c|}
\hline \multirow{2}{*}{ Models } & \multirow{2}{*}{ Effects in the Model } & \multicolumn{2}{|c|}{ Asthma } & \multicolumn{2}{|c|}{ Diabetes } & \multicolumn{2}{|c|}{ Epilepsy } & \multicolumn{2}{|c|}{ CVD } \\
\hline & & Adjusted $\mathrm{R}^{2}$ & $P$ & Adjusted $\mathrm{R}^{2}$ & $P$ & Adjusted $\mathrm{R}^{2}$ & $P$ & Adjusted $\mathrm{R}^{2}$ & $P$ \\
\hline \multirow{8}{*}{ 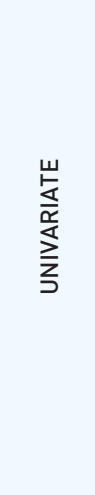 } & Age & 0.0002 & 0.83 & $0.11 *$ & 0.0005 & 0.01 & 0.26 & 0.26 & 0.00001 \\
\hline & Gender & 0.02 & 0.04 & 0.0 & 0.99 & 0.005 & 0.52 & 0.005 & 0.73 \\
\hline & Ethnicity ${ }^{2}$ & 0.019 & 0.09 & 0.02 & 0.15 & 0.03 & 0.64 & 0.005 & 0.27 \\
\hline & Medication Intake (Rx) & 0.006 & 0.30 & 0.12 & 0.001 & 0.06 & 0.03 & 0.12 & 0.00001 \\
\hline & Smoking & 0.01 & 0.51 & 0.03 & 0.10 & 0.02 & 0.70 & 0.006 & 0.23 \\
\hline & Concomitant Infection ${ }^{1}$ & 0.008 & 0.21 & 0.04 & 0.48 & 0.02 & 0.19 & 0.02 & 0.05 \\
\hline & DMFT (above a score of 15 ) & 0.04 & 0.01 & 0.05 & 0.03 & 0.18 & 0.001 & 0.09 & 0.07 \\
\hline & DMFS (above a score of 50 ) & 0.02 & 0.008 & 0.05 & 0.01 & 0.14 & 0.0008 & 0.13 & 0.09 \\
\hline
\end{tabular}

${ }^{1}$ Concomitant Infections include AIDS/HIV, hepatitis, tuberculosis, or recurrent sinus infections

${ }^{2}$ Ethnicity includes Caucasians and African-Americans 
and $\mathrm{Rx}$ had $\mathrm{R}^{2}=0.17$ with the parameter estimate $P=0.19$. Caries experience does not appear to be associated with cardiovascular diseases and diabetes. The models for diabetes showed only age, ethnicity and medication intake to be associated. Similarly, CVD showed only age and medication intake associations.

\section{DISCUSSION}

Here we report analysis of a high risk population for oral and systemic diseases from Pittsburgh and provide data that supports an association between caries experience and specific systemic diseases, namely asthma and epilepsy. Pittsburgh is the largest city in the Appalachian region of the United States, and one of the poorest in the country. Pittsburgh has had fluoridated water since 1953, however, nearly half of the children in Pittsburgh between six and eight have had cavities according to a 2002 State Department of Health report. ${ }^{12}$ More than $70 \%$ of 15 -year-olds in the city have had cavities, the highest percentage in the state. Close to $30 \%$ of the city's children have untreated cavities. That is more than double the state average of $14 \%$.
Medication intake is also shown to influence caries experience and can be viewed as an indicator of access to health care and overall wellbeing. In our population, $48 \%$ of those 48 individuals with asthma and $34 \%$ of those 108 with CVD were not on prescription medications. Only $23 \%$ of the 13 epileptics and only $15 \%$ of the 20 diabetics were not receiving medication.

There were no significant ethnic differences in those without medication ( $P>.20$ for those with diabetes, CVD, epilepsy and asthma).

Asthma is one of the most common chronic medical ailments in children and its frequency has steadily increased in the last two decades. ${ }^{13,14} \mathrm{~A}$ number of studies have investigated oral health in individuals with asthma, but the results are conflicting. Whereas several studies suggested asthmatic children have higher indexes of caries, ${ }^{11,15-23}$ some studies did not find this same correlation. ${ }^{24-27}$ Individuals with asthma appear to accumulate higher amounts of dental biofilm, as well as present with higher salivary levels of mutans streptococci. ${ }^{23} \beta_{2}$ agonists cause decreased saliva secretion rate and patients taking these medications

Table 3. Modeling of diseases: Using multiple effects and interactions.

\begin{tabular}{|c|c|c|c|c|c|}
\hline \multirow[b]{2}{*}{ Disease } & \multirow[b]{2}{*}{ Effects in the Model } & \multirow[b]{2}{*}{ Adjusted $\mathrm{R}^{2}$} & \multicolumn{3}{|c|}{ Parameter estimates $(\beta)$ with their $p$-values \& OR } \\
\hline & & & $\beta$ estimate & $P$ & OR $(95 \% \mathrm{Cl})$ \\
\hline \multirow{6}{*}{ Asthma } & Gender + & \multirow{2}{*}{0.06} & +0.7749 & 0.03 & $2.2(1.1,4.3)$ \\
\hline & DMFT & & +0.0493 & 0.02 & $1.05(1.01,1.1)$ \\
\hline & Gender + & \multirow{2}{*}{0.05} & +0.7484 & 0.03 & $2.1(1.1,4.2)$ \\
\hline & DMFS & & +0.0076 & 0.08 & $1.01(0.99,1.1)$ \\
\hline & Age + & \multirow{2}{*}{0.18} & +0.0498 & 0.001 & $1.1(1.02,1.1)$ \\
\hline & Ethnicity & & +1.3760 & 0.008 & $3.9(1.4,10.9)$ \\
\hline \multirow{10}{*}{ Diabetes } & Age + & \multirow{5}{*}{0.23} & +0.0380 & 0.02 & $1.04(1.01,1.1)$ \\
\hline & Ethnicity + & & +1.4298 & 0.007 & $4.2(1.48,11.8)$ \\
\hline & $\mathrm{Rx}$ & & +1.4536 & 0.03 & $4.3(1.1,16.2)$ \\
\hline & Age + & & +0.0812 & 0.07 & $1.1(0.99,1.2)$ \\
\hline & Ethnicity + & & +0.4108 & 0.66 & $1.5(0.2,9.4)$ \\
\hline & $\mathrm{Rx}+$ & \multirow{3}{*}{0.28} & +2.2810 & 0.03 & $9.8(1.2,79.2)$ \\
\hline & Age*Ethnicity + & & -0.0739 & 0.12 & $0.9(0.8,1.02)$ \\
\hline & Age* Rx & & +0.0695 & 0.11 & $1.072(0.9,1.2)$ \\
\hline & DMFT + & \multirow{2}{*}{0.20} & +0.1888 & 0.003 & $1.2(1.1,1.4)$ \\
\hline & $\mathrm{Rx}$ & & +0.8920 & 0.19 & $2.4(0.6,9.4)$ \\
\hline \multirow{2}{*}{ Epilepsy } & DMFS + & \multirow{2}{*}{0.17} & +0.0262 & 0.002 & $1.02(1.009,1.04)$ \\
\hline & $\mathrm{Rx}$ & & +0.9343 & 0.17 & $2.5(0.7,9.8)$ \\
\hline \multirow{2}{*}{ CVD } & Age + & \multirow{2}{*}{0.28} & +0.0519 & $<0.0001$ & $1.05(1.03,1.07)$ \\
\hline & $\mathrm{Rx}$ & & +0.7288 & 0.01 & $2.1(1 \cdot 2,3.7)$ \\
\hline
\end{tabular}


have increased levels of lactobacilli and mutans streptococci. ${ }^{15,16}$ Although it is possible that medication intake increases susceptibility for caries, our data does not suggest that medications are associated with higher caries experience in asthmatics. Genes in the immune signaling pathway are differentially expressed in asthmatic individu$\mathrm{als}^{28}$ and could underlie the association between asthma and high caries experience. One of these genes is $C D-14$, which is described as a classical example of gene-environment interactive factor in asthma. ${ }^{29}$ Variation in $C D-14$ has been also associated with resistance to abscess or fistula formation in children with four or more caries lesions. ${ }^{30}$ Immune response regulators may be the common factors that underlie the association between asthma and caries.

Asthma is unlikely to be a single disease but rather a series of complex, overlapping individual diseases or phenotypes, each defined by its unique interaction between genetic and environmental factors. These conditions include syndromes characterized by allergen-exacerbated, non-allergic, and aspirin-exacerbated factors along with syndromes best distinguished by their pathologic findings leosinophilic, neutrophilic, pauci-granulocytic), response to therapy (corticosteroid resistant), and natural history (remodeling prone). ${ }^{31}$ The data available for this study is from self-reported medical history and none of the detailed descriptions listed above were available. Allergic sensitization can be detected by a positive skin test result to at least one common allergen in $93.5 \%$ of cases with severe asthma. ${ }^{32}$ Non-allergic asthma has a more likely onset during adulthood, female predominance, and a higher degree of severity. ${ }^{33}$ This is interesting since our results suggest that asthmatic females have a slightly higher caries experience lasthmatic females DMFT $=18.79$ versus asthmatic males DMFT=17.33) although in our study females in general did not (female DMFT=15.29 versus males DMFT=15.42). Females in general have higher caries experience, ${ }^{34}$ and caries contributing genetics factors in the $X$ chromosome have been suggested by our group. ${ }^{35-37}$ Our future investigations aim to identify the genetic factors contributing to caries and how they modulate disease.

Our work also suggests epileptic individuals have a higher caries experience. A Finnish study with 60 females ages 8-18 years and matched controls suggested that caries lesions would be present sooner after eruption of upper first and second molars, and central incisors of epileptic girls. ${ }^{38}$ The authors speculated that factors related to epilepsy, in particular its medication, might increase the risk of caries. However, a previous study compared two groups of epileptic children 8-14 years, one being treated with sodium valproate for one to four years and the other recently diagnosed and had never received the drug. No differences in caries prevalence, oral hygiene state, salivary secretion rate, salivary buffer capacity, and lactobacillus count was found. ${ }^{39}$ Further investigations are warranted aiming to understand the possible relationship between caries experience and epilepsy.

With respect to cardiovascular diseases, our results are in agreement with recent work that suggests that caries and cardiovascular diseases are mostly explained by confounding factors. ${ }^{40}$ In our data, age above 43 years is the best indicator of cardiovascular diseases, a result that is obviously expected. A link between active root caries and cardiac arrhythmias may exist in individuals older than 80 years 9 but our study is not enriched by individuals that old and this possible association would be easily missed by us. Similarly, diabetes is associated with older age. ${ }^{41}$ Our data does not suggest that cardiovascular diseases and diabetes are associated with higher caries experience.

This study has several weaknesses that deserve consideration. Caries data was extracted from clinical patient records and, although we can assume a good level of standardization in the description of the presence of caries lesions, fillings, and extracted teeth due to the fact that the records belong to the same educational institution that follows a single philosophy, still the data can be influenced by variation in the way caries is described. The definitions of systemic diseases we used, although in general are comprehensive, are based on self-reported information, and may lack, in some instances, precision. Regarding the DMFT and DMFS scores, one can argue that they may be inflated in adults by the inherent deficiencies of restorative materials and techniques. In addition, failed fillings are relatively common and replaced with larger ones encroaching on more surfaces. Common periodontal and prosthetic reasons for 
tooth removal, and simple economic choices also can inflate caries scores. Although, we considered these factors when extracting the caries data, the data could still have been influenced by these variables. We did additional modeling just using the number of decayed teeth and the results did not considerable change (data not shown), which may partially suggest that the caries experience data we are using is not heavily influenced by the variables just described above. Caries incidence rates and years of systemic disease experience would have been more desirable measures but this kind of data was not possible to be extrapolated from the majority of individuals studied.

Although our study is based on self-reported medical history, and therefore cannot access in more detail the specific types of the conditions the subject reported, we had the advantage of studying a group at higher risk for systemic diseases and with very high caries experience. This factor likely decreased heterogeneity and improved our ability to find associations. In summary, we report here that asthma and epilepsy are associated with high caries experience in adults. These results are significant because they suggest that individuals suffering from asthma or epilepsy should receive more individualized attention regarding caries prevention.

\section{CONCLUSIONS}

- Asthma is associated with higher caries experience, particularly in females.

- Epilepsy is associated with higher caries experience.

- Caries experience appears to not increase in individuals with cardiovascular diseases or diabetes.

\section{ACKNOWLEDGEMENTS}

The authors are indebted to the individuals that participated in this study. Data for this study was provided by the Dental Registry and DNA Repository of the School of Dental Medicine, University of Pittsburgh. Financial support was provided by the School of Dental Medicine, University of Pittsburgh. IA was supported by the CTSI START UP program, the short term pre-doctoral award through the Clinical and Translational Science Institute and the Institute for Clinical Research Education at the University of Pittsburgh (NIH Grant 5TL1RR024155-02).

\section{REFERENCES}

1. Kay EJ. How often should we go to the dentist? Brit Med J 1999;319:204-205.

2. Manski RJ, Moeller JF, Maas WR. Dental services. An analysis of utilization over 20 years. J Amer Dent Assoc 2001;132:655-664.

3. Green BL, Person S, Crowther M, Frison S, Shipp M, Lee P, Martin M. Demographic and geographic variations of oral health among African Americans based on NHANES III. Community Dent Health 2003;20:117-122.

4. Riley JR III, Gilbert GH, Heft MW. Socioeconomic and demographic disparities in symptoms of orofacial pain. $J P u b-$ lic Health Dent 2003;63:166-173.

5. Cohen LA, Manski RJ. Visits to non-dentist health care providers for dental problems. Fam Med 2006;38:556-564.

6. Lutfiyya MN, Nika B, Ng L, Tragos C, Won R, Lipsky MS. Primary prevention of overweight and obesity: an analysis of national survey data. J Gen Intern Med 2008;23:821-823.

7. American Medical Association. Medical evaluation of healthy persons. Council on Scientific Affairs. J Amer Med Assoc 1983;249:1626-1633.

8. World Health Organization. The world oral health report 2003. 38pp, 2003.

9. Holm-Pedersen P, Avlund K, Morse DE, Stolze K, Katz RV, Viitanen M, Winblad B. Dental caries, periodontal disease, and cardiac arrhythmias in community-dwelling older persons aged 80 and older: is there a link? J Am Geriatr Soc 2005;53:430-437.

10. Dye BA, Wang R, Lashley R, Wei R, Abnet CC, Wang G, Dawsey SM, Cong W, Roth MJ, Li X, Qiao Y. Using NHANES oral health examination protocols as part of an esophageal cancer screening study conducted in a high-risk region of China. BMC Oral Health 2007; 17:10.

11. Stensson M, Wendt LK, Koch G, Oldaeus G, Birkhed D. Oral health in preschool children with asthma. Int $J$ Paediatr Dent 2008;18:243-250.

12. PA Department of Health. Status of oral health in Pennsylvania. $51 \mathrm{pp}, 2002$.

13. Mannino DM, Homa DM, Pertowski CA, Ashizawa A, Nixon LL, Johnson CA, Ball LB, Jack E, Kang DS. Surveillance for asthma - United States, 1960-95. MMWR CDC Surveill Summ 1998;47:1-27.

14. Steinbacher DM, Glick M. The dental patient with asthma. An update and oral health considerations. J Amer Dent Assoc 2001;132:1229-1239.

15. Ryberg M, Moller C, Ericson T. Effect of beta 2-adrenoceptor agonists on saliva proteins and dental caries in asthmatic children. J Dent Res 1987;66:1404-1406. 
16. Ryberg M, Moller C, Ericson T. Saliva composition and caries development in asthmatic patients treated with beta 2-adrenoceptor agonists: a 4-year follow-up study. Scand $J$ Dent Res 1991;99:212-218.

17. Arnrup K, Lundin SA, Dahllöf G. Analysis of paediatric dental services provided at a regional hospital in Sweden. Dental treatment need in medically compromised children referred for consultation. Swed Dental J 1993;17:255-259.

18. McDerra EJ, Pollard MA, Curzon ME. The dental status of asthmatic British school children. Pediatr Dent 1998;20:281-287.

19. Milano M. Increased risk for dental caries in asthmatic children. Tex Dent $J$ 1999;116:35-42.

20. Reddy DK, Hegde AM, Munshi AK. Dental caries status of children with bronchial asthma. J Clin Pediatr Dent 2003;27:293-295.

21. Ersin NK, Gülen F, Eronat N, Cogulu D, Demir E, Tanaç R, Aydemir S. Oral and dental manifestations of young asthmatics related to medication, severity and duration of condition. Pediatr Int 2006;48:549-554.

22. Milano M, Lee JY, Donovan K, Chew JW. A cross-sectional study of medication-related factors and caries experience in asthmatic children. Pediatr Dent 2006;28:415-419.

23. Ferreira FBA, Botelho MPJ, Fernandes KBP, Dezan CC, Pinto LMCP, Chimentão LK, Cerci Neto A. Levels of cariogenic microorganisms and oral conditions of asthmatic children. Abstracts of the $86^{\text {th }}$ General Session \& Exhibition of the International Association for Dental Research 2008; $1: 3582$.

24. Bjerkeborn K, Dahllöf G, Hedlin G, Lindell M, Modéer T. Effect of disease severity and pharmacotherapy of asthma on oral health in asthmatic children. Scand $J$ Dent Res 1987;95:159-164.

25. Meldrum AM, Thomson WM, Drummond BK, Sears MR. Is asthma a risk factor for dental caries? Finding from a cohort study. Caries Res 2001;35:235-239.

26. Shulman JD, Taylor SE, Nunn ME. The association between asthma and dental caries in children and adolescents: a population-based case-control study. Caries Res 2001;35:240-244.

27. Ellot AK, Vanobbergen JN, De Baets F, Martens LC. Oral health and habits in children with asthma related to severity and duration of condition. Eur J Paediatr Dent 2004;5:210215.

28. Schmidt-Weber CB. Gene expression profiling in allergy and asthma. Chem Immunol Allergy 2006;91:188-194.

29. Simpson A, John SL, Jury F, Niven R, Woodcock A, Ollier WE, Custovic A. Endotoxin exposure, CD14, and allergic disease: an interaction between genes and the environment. Am J Respir Crit Care Med 2006;174:386-392.
30. De Soet JJ, van Gemert-Schriks MC, Laine ML, van Amerongen WE, Morré SA, van Winkelhoff AJ. Host and microbiological factors related to dental caries development. Caries Res 2008;42:340-347.

31. Borish L, Culp JA. Asthma: a syndrome composed of heterogeneous diseases. Ann Allergy Asthma Immunol 2008;101:1-8

32. Expert Panel Report 3 (EPR-3). Guidelines for the diagnosis and management of asthma - Summary Report 2007. $J$ Allergy Clin Immunol 2007;120(5 Suppl):S94-S138.

33. Bell EH. Clinical phenotypes of asthma. Curr Opin Pulm Med 2004; 10:44-50.

34. Lukacs JR, Largaespada LL. Explaining sex differences in dental caries prevalence: saliva, hormones, and “life-history" etiologies. Am J Hum Biol 2006;18:540-555.

35. Deeley K, Letra A, Rose EK, Brandon CA, Resick JM, Marazita ML, Vieira AR. Possible association of amelogenin to high caries experience in a Guatemalan-Mayan population. Caries Res 2008;42:8-13.

36. Patir A, Seymen F, Yildirim M, Deeley K, Cooper ME, Marazita ML, Vieira AR. Enamel formation genes are associated with high caries experience in Turkish children. Caries Res 2008;42:394-400.

37. Vieira AR, Marazita ML, McHenry TG. Genome-wide scan finds suggestive caries loci. J Dent Res 2008;87:435-439.

38. Rajavaara P, Vainionpää L, Rättyä J, Knip M, Pakarinen A, Isojärvi J, Larmas M. Tooth by tooth survival analysis of dental health in girls with epilepsy. Eur J Paediatr Dent 2003;4:72-77.

39. Eeg-Olofsson O, Lundström A, Hamp SE. Oral state of children with epilepsy on treatment with sodium valproate. Scand J Dent Res 1983;91:219-223.

40. Tuominen R, Reunanen A, Paunio M, Paunio I, Aromaa A. Oral health indicators poorly predict coronary heart disease deaths. J Dent Res 2003;82:713-718.

41. Deshpande AD, Harris-Hayes M, Schootman M. Epidemiology of diabetes and diabetes-related complications. Phys Ther 2008;88:1254-1264. 